\title{
Weak and Strong Convergence Theorems for Strictly Pseudononspreading Mappings and Equilibrium Problem in Hilbert Spaces
}

\author{
Yun He Zhao and Shih-sen Chang \\ College of Statistics and Mathematics, Yunnan University of Finance and Economics, Kunming, Yunnan 650221, China \\ Correspondence should be addressed to Shih-sen Chang; changss2013@aliyun.com
}

Received 14 June 2013; Revised 10 August 2013; Accepted 24 August 2013

Academic Editor: Abdelghani Bellouquid

Copyright (C) 2013 Y. H. Zhao and S.-s. Chang. This is an open access article distributed under the Creative Commons Attribution License, which permits unrestricted use, distribution, and reproduction in any medium, provided the original work is properly cited.

The purpose of this paper is to propose an iterative algorithm for equilibrium problem and a class of strictly pseudononspreading mappings which is more general than the class of nonspreading mappings studied recently in Kurokawa and Takahashi (2010). We explored an auxiliary mapping in our theorems and proofs and under suitable conditions, some weak and strong convergence theorems are proved. The results presented in the paper extend and improve some recent results announced by some authors.

\section{Introduction and Preliminaries}

Throughout this paper, we assume that $H$ is a real Hilbert space and $C$ is a nonempty and closed convex subset of $H$. In the sequel, we denote by " $x_{n} \rightarrow x$ " and " $x_{n} \rightarrow x$ " the strong and weak convergence of $\left\{x_{n}\right\}$, respectively. Denote by $F(T)$ the set of fixed points of a mapping $T$.

Definition 1. Let $T: C \rightarrow C$ be a mapping.

(1) $T$ is said to be nonexpansive, if $\|T x-T y\| \leq\|x-y\|$, $\forall x, y \in C$.

(2) $T$ is said to be quasinonexpansive, if $F(T)$ is nonempty and

$$
\|T x-p\| \leq\|x-p\|, \quad \forall x \in C, p \in F(T) .
$$

(3) $T$ is said to be nonspreading $[1,2]$, if

$$
2\|T x-T y\|^{2} \leq\|T x-y\|^{2}+\|T y-x\|^{2}, \quad \forall x, y \in C .
$$

It is easy to prove that $T: C \rightarrow C$ is nonspreading if and only if

$$
\|T x-T y\|^{2} \leq\|x-y\|^{2}+2\langle x-T x, y-T y\rangle \quad \forall x, y \in C .
$$

(4) $T: C \rightarrow H$ is said to be $k$-strictly pseudononspreading in the terminology of Browder-Petryshyn [3], if there exists $k \in[0,1)$ such that

$$
\begin{aligned}
\|T x-T y\|^{2} \leq & \|x-y\|^{2}+k\|x-T x-(y-T y)\|^{2} \\
& +2\langle x-T x, y-T y\rangle \quad \forall x, y \in C .
\end{aligned}
$$

Remark 2. (1) If $T: C \rightarrow C$ is a nonspreading mapping with $F(T) \neq \emptyset$, then $T$ is quasinonexpansive and $F(T)$ is closed and convex.

(2) Clearly every nonspreading mapping is $k$-strictly pseudononspreading with $k=0$, but the inverse is not true. This can be seen from the following example.

Example 3. Let $\mathscr{R}$ denote the set of all real numbers. Let $T$ : $\mathscr{R} \rightarrow \mathscr{R}$ be a mapping defined by

$$
T x= \begin{cases}x, & x \in(-\infty, 0), \\ -2 x, & x \in[0, \infty)\end{cases}
$$

It is easy to see that $T$ is a $k$-strictly pseudononspreading mapping with $k \in[0,1$ ), but it is not nonspreading (see, [4]). 
Definition 4. (1) Let $T: H \rightarrow H$ be a mapping. $I-T$ is said to be demiclosed at 0 , if for any sequence $\left\{x_{n}\right\} \subset H$ with $x_{n} \rightarrow x^{*}$ and $\left\|(I-T) x_{n}\right\| \rightarrow 0$, we have $x^{*}=T x^{*}$.

(2) A Banach space $E$ is said to have Opial's property, if for any sequence $\left\{x_{n}\right\} \subset E$ with $x_{n} \rightarrow x^{*}$, we have

$\liminf _{n \rightarrow \infty}\left\|x_{n}-x^{*}\right\|<\liminf _{n \rightarrow \infty}\left\|x_{n}-y\right\|, \quad \forall y \in E$ with $y \neq x^{*}$.

It is well known that each Hilbert space processes opial property.

(3) A mapping $S: C \rightarrow C$ is said to be semicompact, if for any bounded sequence $\left\{x_{n}\right\} \subset C$ with $\lim _{n \rightarrow \infty}\left\|x_{n}-S x_{n}\right\|=0$, then there exists a subsequence $\left\{x_{n_{i}}\right\} \subset\left\{x_{n}\right\}$ such that $\left\{x_{n_{i}}\right\}$ converges strongly to some point $x^{*} \in C$.

Lemma 5 (see [5]). Let E be a uniformly convex Banach space and let $B_{r}(0):=\{x \in E:\|x\| \leq r\}$ be a closed ball with center 0 and radius $r>0$. For any given sequence $\left\{x_{1}, x_{2}, \ldots, x_{n}, \ldots\right\} \subset$ $B_{r}(0)$ and any given number sequence $\left\{\lambda_{1}, \lambda_{2}, \ldots, \lambda_{n}, \ldots\right\}$ with $\lambda_{i} \geq 0, \sum_{i=1}^{\infty} \lambda_{i}=1$, there exists a continuous strictly increasing and convex function $g:[0,2 r) \rightarrow[0, \infty)$ with $g(0)=0$ such that for any $i, j \in \mathcal{N}, i<j$ the following holds:

$$
\left\|\sum_{n=1}^{\infty} \lambda_{n} x_{n}\right\|^{2} \leq \sum_{n=1}^{\infty} \lambda_{n}\left\|x_{n}\right\|^{2}-\lambda_{i} \lambda_{j} g\left(\left\|x_{i}-x_{j}\right\|\right) .
$$

Lemma 6. Let $H$ be a real Hilbert space, $C$ be a nonempty and closed convex subset of $H$, and let $T: C \rightarrow C$ be a $k$-strictly pseudononspreading mapping.

(i) If $F(T) \neq \emptyset$, then it is closed and convex.

(ii) $(I-T)$ is demiclosed at origin.

Lemma 7. Let $T: C \rightarrow C$ be a $k$-strictly pseudononspreading mapping with $k \in[0,1)$. Denote by $T_{\beta}:=\beta I+(1-\beta) T$, where $\beta \in[k, 1)$, then

(i) $F(T)=F\left(T_{\beta}\right)$;

(ii) the following inequality holds:

$$
\begin{array}{r}
\left\|T_{\beta} x-T_{\beta} y\right\|^{2} \leq\|x-y\|^{2}+\frac{2}{1-\beta}\left\langle x-T_{\beta} x, y-T_{\beta} y\right\rangle, \\
\forall x, y \in C ;
\end{array}
$$

(iii) $T_{\beta}$ is a quasinonexpansive mapping, that is,

$$
\left\|T_{\beta} x-p\right\|^{2} \leq\|x-p\|^{2}, \quad \forall x \in C, p \in F(T) .
$$

Proof. The conclusion (i) is obvious. Now we prove the conclusion (ii). Since $T$ is $k$-strictly pseudononspreading, for any $x, y \in C$ we have

$$
\begin{aligned}
\left\|T_{\beta} x-T_{\beta} y\right\|^{2} & =\|\beta(x-y)+(1-\beta)(T x-T y)\|^{2} \\
& =\beta\|x-y\|^{2}+(1-\beta)\|T x-T y\|^{2}
\end{aligned}
$$

$$
\begin{aligned}
& -\beta(1-\beta)\|x-T x-(y-T y)\|^{2} \\
\leq & \beta\|x-y\|^{2}+(1-\beta) \\
& \times\left\{\|x-y\|^{2}+k\|x-T x-(y-T y)\|^{2}\right. \\
& +2\langle x-T x, y-T y\rangle\} \\
& -\beta(1-\beta)\|x-T x-(y-T y)\|^{2} \\
= & \|x-y\|^{2}+2(1-\beta)\langle x-T x, y-T y\rangle \\
& -(1-\beta)(\beta-k)\|x-T x-(y-T y)\|^{2} \\
\leq & \|x-y\|^{2}+2(1-\beta)\langle x-T x, y-T y\rangle \\
= & \|x-y\|^{2}+\frac{2}{(1-\beta)}\left\langle x-T \beta x, y-T_{\beta} y\right\rangle .
\end{aligned}
$$

Take $y \in F(T)$ in (8), then $y \in F\left(T_{\beta}\right)$. Hence, conclusion (iii) is proved.

This completes the proof.

In the sequel, we assume that $\phi: C \times C \rightarrow \mathscr{R}$ is a bifunction satisfying the following conditions:

(A1) $\phi(x, x)=0, \forall x \in C$;

(A2) $\phi$ is monotone, that is, $\phi(x, y)+\phi(y, x) \leq 0, \forall x, y \in C$;

(A3) $\lim _{t \downarrow 0} \phi(t z+(1-t) x, y) \leq \phi(x, y), \forall x, y, z \in C$;

(A4) for each $x \in C, y \mapsto \phi(x, y)$ is convex and lower semicontinuous.

Recalled that the "so-called" equilibrium problem for a bifunction function $\phi$ is to find a point $x^{*} \in C$, such that

$$
\phi\left(x^{*}, y\right) \geq 0, \quad \forall y \in C .
$$

Lemma 8 (see $[6,7])$. Let $C$ be a nonempty and closed convex subset of a Hilbert space $H$ and let $\phi: C \times C \rightarrow \mathscr{R}$ be a bi-function satisfying conditions: (A1), (A2), (A3), and (A4). Then, for any $r>0$ and $x \in C$, there exists $z \in C$ such that

$$
\phi(z, y)+\frac{1}{r}\langle y-z, z-x\rangle \geq 0, \quad \forall y \in C .
$$

Furthermore, if for given $r>0$, we define a mapping $T_{r}: C \rightarrow$ C by

$$
T_{r} x:=\left\{z \in C: \phi(z, y)+\frac{1}{r}\langle y-z, z-x\rangle \geq 0, \forall y \in C\right\},
$$

then the following hold:

(1) $T_{r}$ is single-valued;

(2) $T_{r}$ is firmly nonexpansive, that is, $\left\|T_{r} x-T_{r} y\right\|^{2} \leq$ $\left\langle T_{r} x-T_{r} y, x-y\right\rangle$;

(3) $F\left(T_{r}\right)=\Omega$, where $\Omega$ is the set of solutions of the equilibrium problem (11);

(4) $\Omega$ is a closed and convex subset of $C$. 
Concerning the weak and strong convergence problem for some kinds of iterative algorithms for nonspreading mappings, $k$-strictly pseudononspreading mappings and other kind of nonlinear mappings have been considered in Osilike and Isiogugu [4], Igarashi et al. [8], Iemoto and Takahashi [9], Kurokawa and Takahashi [10], and Kim [11-28]. The purpose of this paper is to propose an iterative algorithm for an infinite family of strictly pseudononspreading mappings and equilibrium problem. Under suitable conditions, some weak and strong convergence theorems are proved. The results presented in the paper extend and improve the corresponding results in $[4,8-11]$.

\section{Main Results}

Throughout this section, we assume that the following conditions are satisfied.

(1) $H$ is a real Hilbert spaces, $C$ is a nonempty and close convex subset of $H$.

(2) For each $S_{i}: C \rightarrow C, i=1,2, \ldots$ is a $k_{i}$-strictly pseudononspreading mapping with $k:=\sup _{i \geq 1} k_{i} \epsilon$ $(0,1)$. For given $\beta \in[k, 1)$, denoted by $S_{i, \beta}:=\beta I+$ $(1-\beta) S_{i}$, for each $i=1,2, \ldots$, it follows from (8) that

$$
\begin{aligned}
\left\|S_{i, \beta} x-S_{i, \beta} y\right\|^{2} & \\
\leq & \|x-y\|^{2} \\
& +\frac{2}{1-\beta}\left\langle x-S_{i, \beta} x, y-S_{i, \beta} y\right\rangle, \quad \forall x, y \in C .
\end{aligned}
$$

(3) $\phi: C \times C \rightarrow \mathscr{R}$ is a bifunction satisfying the conditions (A1)-(A4). Then it follows from Lemma 8 that the mapping $T_{r}$ defined by (13) is single valued, $z=$ $T_{r} x, F\left(T_{r}\right)=\Omega$ (where $\Omega$ is the solution set of the equilibrium problem (11)), and $\Omega$ is a closed and convex subset of $C$.

We are now in a position to give the following result.

Theorem 9. Let $H, C,\left\{S_{i}\right\}, k, \beta,\left\{S_{i, \beta}\right\}, \phi, T_{r}$, and $\Omega$ be the same as above. Let $\left\{x_{n}\right\}$ and $\left\{u_{n}\right\}$ be the sequences defined by

$$
\left\{\begin{array}{l}
x_{1} \in C \quad \text { chosen arbitrarily, } \\
\phi\left(u_{n}, y\right)+\frac{1}{r_{n}}\left\langle y-u_{n}, u_{n}-x_{n}\right\rangle \geq 0, \quad \forall y \in C, \\
x_{n+1}=\alpha_{0, n} u_{n}+\sum_{i=1}^{\infty} \alpha_{i, n} S_{i, \beta} u_{n},
\end{array}\right.
$$

where $\left\{\alpha_{i, n}\right\} \subset(0,1)$ and $\left\{r_{n}\right\}$ satisfy the following conditions:
(a) $\sum_{i=0}^{\infty} \alpha_{i, n}=1$, for each $n \geq 1$;
(b) for each $i \geq 1, \liminf _{n \rightarrow \infty} \alpha_{0, n} \alpha_{i, n}>0$;
(c) $\left\{r_{n}\right\} \subset(0, \infty)$ and $\liminf _{n \rightarrow \infty} r_{n}>0$.
(I) If $\mathscr{F}:=\left(\bigcap_{i=1}^{\infty} F\left(S_{i}\right)\right) \bigcap \Omega \neq \emptyset$, then both $\left\{x_{n}\right\}$ and $\left\{u_{n}\right\}$ converge weakly to some point $x^{*} \in \mathscr{F}$;

(II) in addition, if there exists some positive integer $m$ such that $S_{m}$ is semicompact, then both $\left\{x_{n}\right\}$ and $\left\{u_{n}\right\}$ converge strongly to $x^{*} \in \mathscr{F}$;

Proof. First, we prove the conclusion (I). The proof is divided into three steps.

Step 1. We prove that the sequences $\left\{x_{n}\right\},\left\{u_{n}\right\},\left\{S_{i, \beta} u_{n}\right\}$, and $\left\{S_{i, \beta} x_{n}\right\}, i \geq 1$ all are bounded, and for each $p \in \mathscr{F}$ the limits $\lim _{n \rightarrow \infty}\left\|x_{n}-p\right\|, \lim _{n \rightarrow \infty}\left\|u_{n}-p\right\|$ exist and

$$
\lim _{n \rightarrow \infty}\left\|x_{n}-p\right\|=\lim _{n \rightarrow \infty}\left\|u_{n}-p\right\| .
$$

In fact, it follows from Lemma 8 that $u_{n}=T_{r_{n}} x_{n}, p=$ $T_{r_{n}} p$, and

$$
\left\|u_{n}-p\right\|=\left\|T_{r_{n}} x_{n}-T_{r_{n}} p\right\| \leq\left\|x_{n}-p\right\|, \quad \forall n \geq 1 .
$$

Since $p \in \mathscr{F}$, by Lemma 7(i), $p \in \bigcap_{i=1}^{\infty} F\left(S_{i, \beta}\right)$. Hence, it follows from (17) and (9) that

$$
\begin{aligned}
\left\|x_{n+1}-p\right\| & =\left\|\alpha_{0, n} u_{n}+\sum_{i=1}^{\infty} \alpha_{i, n} S_{i, \beta} u_{n}-p\right\| \\
& \leq \alpha_{0, n}\left\|u_{n}-p\right\|+\sum_{i=1}^{\infty} \alpha_{i, n}\left\|S_{i, \beta} u_{n}-p\right\| \\
& \leq \alpha_{0, n}\left\|u_{n}-p\right\|+\sum_{i=1}^{\infty} \alpha_{i, n}\left\|u_{n}-p\right\| \\
& =\left\|u_{n}-p\right\| \leq\left\|x_{n}-p\right\|, \quad \forall n \geq 1 .
\end{aligned}
$$

This implies that for each $p \in \mathscr{F}$, the $\operatorname{limits}_{\lim _{n \rightarrow \infty}}\left\|x_{n}-p\right\|$ and $\lim _{n \rightarrow \infty}\left\|u_{n}-p\right\|$ exist. And so $\left\{x_{n}\right\}$ and $\left\{u_{n}\right\}$ are bounded and (16) holds.

Furthermore, by (9), it is easy to see that for each $i \geq 1$, $\left\{S_{i, \beta} u_{n}\right\}$ and $\left\{S_{i, \beta} x_{n}\right\}$ are also bounded.

Step 2. Next we prove that for each $i \geq 1$ the following holds:

$$
\lim _{n \rightarrow \infty}\left\|x_{n}-S_{i} x_{n}\right\|=\lim _{n \rightarrow \infty}\left\|u_{n}-S_{i} u_{n}\right\|=0 .
$$

In fact, by Lemma 5 for any positive integer $i \geq 1$ and $p \in \mathscr{F}$, we have

$$
\begin{aligned}
\left\|x_{n+1}-p\right\|^{2}= & \left\|\alpha_{0, n}\left(u_{n}-p\right)+\sum_{i=1}^{\infty} \alpha_{i, n}\left(S_{i, \beta} u_{n}-p\right)\right\|^{2} \\
\leq & \alpha_{0, n}\left\|u_{n}-p\right\|^{2}+\sum_{i=1}^{\infty} \alpha_{i, n}\left\|S_{i, \beta} u_{n}-p\right\|^{2} \\
& -\alpha_{0, n} \alpha_{i, n} g\left(\left\|u_{n}-S_{i, \beta} u_{n}\right\|\right) \\
\leq & \alpha_{0, n}\left\|u_{n}-p\right\|^{2}+\sum_{i=1}^{\infty} \alpha_{i, n}\left\|u_{n}-p\right\|^{2} \\
& -\alpha_{0, n} \alpha_{i, n} g\left(\left\|u_{n}-S_{i, \beta} u_{n}\right\|\right) \\
\leq & \left\|u_{n}-p\right\|^{2}-\alpha_{0, n} \alpha_{i, n} g\left(\left\|u_{n}-S_{i, \beta} u_{n}\right\|\right) \\
\leq & \left\|x_{n}-p\right\|^{2}-\alpha_{0, n} \alpha_{i, n} g\left(\left\|u_{n}-S_{i, \beta} u_{n}\right\|\right) .
\end{aligned}
$$


This shows that

$$
\begin{aligned}
\alpha_{0, n} \alpha_{i, n} g\left(\left\|u_{n}-S_{i, \beta} u_{n}\right\|\right) & \\
\leq & \left\|x_{n}-p\right\|^{2} \\
& \quad-\left\|x_{n+1}-p\right\|^{2} \longrightarrow 0 \quad(\text { as } n \longrightarrow \infty) .
\end{aligned}
$$

Since $g$ is a continuous and strictly increasing function with $g(0)=0$. By condition (b), it yields that

$$
\lim _{n \rightarrow \infty}\left\|u_{n}-S_{i, \beta} u_{n}\right\|=0
$$

Therefore, we have

$$
\lim _{n \rightarrow \infty}\left\|u_{n}-S_{i} u_{n}\right\|=\lim _{n \rightarrow \infty} \frac{1}{1-\beta}\left\|u_{n}-S_{i, \beta} u_{n}\right\|=0 .
$$

On the other hand, it follows from Lemma 8 that $u_{n}=T_{r_{n}} x_{n}$ and for each $p \in \mathscr{F}$

$$
\begin{aligned}
\left\|u_{n}-p\right\|^{2} & =\left\|T_{r_{n}} x_{n}-T_{r_{n}} p\right\|^{2} \leq\left\langle T_{r_{n}} x_{n}-T_{r_{n}} p, x_{n}-p\right\rangle \\
& =\left\langle u_{n}-p, x_{n}-p\right\rangle \\
& =\frac{1}{2}\left\{\left\|u_{n}-p\right\|^{2}+\left\|x_{n}-p\right\|^{2}-\left\|x_{n}-u_{n}\right\|^{2}\right\} .
\end{aligned}
$$

This shows that

$$
\left\|u_{n}-p\right\|^{2} \leq\left\|x_{n}-p\right\|^{2}-\left\|x_{n}-u_{n}\right\|^{2} .
$$

In view of (20) and (25)

$$
\left\|x_{n+1}-p\right\|^{2} \leq\left\|u_{n}-p\right\|^{2} \leq\left\|x_{n}-p\right\|^{2}-\left\|x_{n}-u_{n}\right\|^{2},
$$

that is

$$
\left\|x_{n}-u_{n}\right\|^{2} \leq\left\|x_{n}-p\right\|^{2}-\left\|x_{n+1}-p\right\|^{2} \longrightarrow 0 \quad(\text { as } n \longrightarrow \infty) .
$$

In view of (27), (22), (14), and noting that $\left\{x_{n}-S_{i, \beta} x_{n}\right\}$ is bounded, we have

$$
\begin{aligned}
& \left\|x_{n}-S_{i, \beta} x_{n}\right\| \\
& \leq\left\|x_{n}-u_{n}\right\|+\left\|u_{n}-S_{i, \beta} u_{n}\right\|+\left\|S_{i, \beta} u_{n}-S_{i, \beta} x_{n}\right\| \\
& \leq\left\|x_{n}-u_{n}\right\|+\left\|u_{n}-S_{i, \beta} u_{n}\right\| \\
& \quad+\left\{\left\|x_{n}-u_{n}\right\|^{2}+\frac{2}{1-\beta}\left|\left\langle u_{n}-S_{i, \beta} u_{n}, x_{n}-S_{i, \beta} x_{n}\right\rangle\right|\right\}^{1 / 2} \\
& \longrightarrow 0 \quad(\text { as } n \longrightarrow \infty) .
\end{aligned}
$$

Therefore, we have

$$
\lim _{n \rightarrow \infty}\left\|x_{n}-S_{i} x_{n}\right\|=\lim _{n \rightarrow \infty} \frac{1}{1-\beta}\left\|x_{n}-S_{i, \beta} x_{n}\right\|=0 .
$$

The conclusion is proved.

Step 3. Next we prove that the weak-accumulation point set $W_{\omega}\left(x_{n}\right)$ of the sequence $\left\{x_{n}\right\}$ is a singleton and $W_{\omega}\left(x_{n}\right) \subset \mathscr{F}$.
In fact, for any $w \in W_{\omega}\left(x_{n}\right)$, their exists a subsequence $\left\{x_{n_{i}}\right\} \subset\left\{x_{n}\right\}$ such that $x_{n_{i}} \rightarrow w$. It follows from (27) that $u_{n_{i}} \rightarrow w$. Since $u_{n}=T_{r_{n}} x_{n}$, from (15) and condition (A2) we have

$$
\left\langle y-u_{n_{i}}, \frac{1}{r_{n_{i}}}\left(u_{n_{i}}-x_{n_{i}}\right)\right\rangle \geq \phi\left(y, u_{n_{i}}\right), \quad \forall y \in C .
$$

Since $\left(1 / r_{n_{i}}\right)\left(u_{n_{i}}-x_{n_{i}}\right) \rightarrow 0\left(\right.$ as $\left.n_{i} \rightarrow \infty\right)$ and $u_{n_{i}} \rightarrow w$, it follows from condition (A4) that

$$
\phi(y, w) \leq 0, \quad \forall y \in C .
$$

For any $t \in(0,1), y \in C$, letting $y_{t}=t y+(1-t) w$, then $y_{t} \in C$. By condition (A1) and (A4), we have

$$
0=\phi\left(y_{t}, y_{t}\right) \leq t \phi\left(y_{t}, y\right)+(1-t) \phi\left(y_{t}, w\right) \leq t \phi\left(y_{t}, y\right) .
$$

This implies that $\phi\left(y_{t}, y\right) \geq 0$. Letting $t \rightarrow 0$, by condition (A3) we have

$$
\phi(w, y) \geq 0, \quad \forall y \in C .
$$

This shows that $w \in C$ is a solution to the equilibrium (11), that is, $w \in \Omega$.

On the other hand, by Lemma 6 , for each $i \geq 1, I-S_{i}$ is demiclosed at 0 . In view of (19), we know that $w \in \mathscr{F}$. Due to the arbitrariness of $w \in W_{\omega}\left(x_{n}\right)$, we have $W_{\omega}\left(x_{n}\right) \subset \mathscr{F}$.

Now we prove that $W_{\omega}\left(x_{n}\right)$ is a singleton. Suppose to the contrary that there exist $x^{*}, y^{*} \in W_{\omega}\left(x_{n}\right)$ with $x^{*} \neq y^{*}$. Therefore, there exist subsequences $\left\{x_{n_{i}}\right\}$ and $\left\{x_{n_{j}}\right\}$ in $\left\{x_{n}\right\}$ such that $x_{n_{i}} \rightarrow x^{*}$ and $x_{n_{j}} \rightarrow y^{*}$. Since $x^{*}, y^{*} \in \mathscr{F}$, by (16), the limits $\lim _{n \rightarrow \infty}\left\|x_{n}-x^{*}\right\|$ and $\lim _{n \rightarrow \infty}\left\|x_{n}-y^{*}\right\|$ exist. By using the opial property of $H$, we have

$$
\begin{aligned}
\liminf _{n_{i} \rightarrow \infty}\left\|x_{n_{i}}-x^{*}\right\| & <\liminf _{n_{i} \rightarrow \infty}\left\|x_{n_{i}}-y^{*}\right\|=\lim _{n \rightarrow \infty}\left\|x_{n}-y^{*}\right\| \\
& =\lim _{n_{j} \rightarrow \infty}\left\|x_{n_{j}}-y^{*}\right\|<\liminf _{n_{j} \rightarrow \infty}\left\|x_{n_{j}}-x^{*}\right\| \\
& =\lim _{n \rightarrow \infty}\left\|x_{n}-x^{*}\right\|=\liminf _{n_{i} \rightarrow \infty}\left\|x_{n_{i}}-x^{*}\right\| .
\end{aligned}
$$

This is a contradiction. Therefore, $W_{\omega}\left(x_{n}\right)$ is a singleton. Without loss of generality, we can assume that $W_{\omega}\left(x_{n}\right)=\left\{x^{*}\right\}$ and $x_{n} \rightarrow x^{*}$. By using (15) and (19), we have $u_{n} \rightarrow x^{*}$.

This completes the proof of the conclusion (I).

Next we prove the conclusion (II).

Without loss of generality, we can assume that $S_{1}$ is semicompact. From (19) we have that

$$
\left\|x_{n}-S_{1} x_{n}\right\| \longrightarrow 0 \quad(\text { as } n \longrightarrow \infty) .
$$

Therefore, there exists a subsequence of $\left\{x_{n_{i}}\right\} \subset\left\{x_{n}\right\}$ such that $x_{n_{i}} \rightarrow u^{*} \in C$. Since $x_{n_{i}} \rightarrow x^{*}$, we have $x^{*}=u^{*}$ and so $x_{n_{i}} \rightarrow x^{*} \in \mathscr{F}$. By virtue of (16), we have

$$
\lim _{n \rightarrow \infty}\left\|u_{n}-x^{*}\right\|=0, \quad \lim _{n \rightarrow \infty}\left\|x_{n}-x^{*}\right\|=0,
$$

This completes the proof of Theorem 9. 
Taking $\phi \equiv 0$ and $r_{n}=1$, for all $n \geq 1$ in Theorem 9, we have $x_{n}=u_{n}$, for all $n \geq 1$, Therefore, the following theorem can be obtained from Theorem 9 immediately.

Theorem 10. Let $H, C,\left\{S_{i}\right\}, k, \beta$ and $\left\{S_{i, \beta}\right\}$ be the same as in Theorem 9. Let $\left\{x_{n}\right\}$ be the sequences defined by

$$
\left\{\begin{array}{l}
x_{1} \in C, \quad \text { chosen arbitrarily, } \\
x_{n+1}=\alpha_{0, n} x_{n}+\sum_{i=1}^{\infty} \alpha_{i, n} S_{i, \beta} x_{n}
\end{array}\right.
$$

where $\left\{\alpha_{i, n}\right\} \subset(0,1)$ satisfies the following conditions:

(a) $\sum_{i=0}^{\infty} \alpha_{i, n}=1$, for each $n \geq 1$;

(b) for each $i \geq 1, \liminf _{n \rightarrow \infty} \alpha_{0, n} \alpha_{i, n}>0$.

(I) If $\mathscr{F}:=\left(\bigcap_{i=1}^{\infty} F\left(S_{i}\right)\right) \neq \emptyset$, then both $\left\{x_{n}\right\}$ converge weakly to some point $x^{*} \in \mathscr{F}$;

(II) in addition, if there exists some positive integer $m$ such that $S_{m}$ is semicompact, then $\left\{x_{n}\right\}$ converge strongly to $x^{*} \in \mathscr{F}$.

Remark 11. Theorems 9 and 10 improve and extend the corresponding recent results of $[4,8-11]$.

\section{Acknowledgments}

The authors would like to express their thanks to the referees for their helpful comments and advices. This work was supported by the Natural Science Foundation of Yunnan Province (Grant no. 2011FB074).

\section{References}

[1] F. Kohsaka and W. Takahashi, "Fixed point theorems for a class of nonlinear mappings related to maximal monotone operators in Banach spaces," Archiv der Mathematik, vol. 91, no. 2, pp. 166177, 2008.

[2] F. Kohsaka and W. Takahashi, "Existence and approximation of fixed points of firmly nonexpansive-type mappings in Banach spaces," SIAM Journal on Optimization, vol. 19, no. 2, pp. 824$835,2008$.

[3] F. E. Browder and W. V. Petryshyn, "Construction of fixed points of nonlinear mappings in Hilbert space," Journal of Mathematical Analysis and Applications, vol. 20, pp. 197-228, 1967.

[4] M. O. Osilike and F. O. Isiogugu, "Weak and strong convergence theorems for nonspreading-type mappings in Hilbert spaces," Nonlinear Analysis. Theory, Methods \& Applications, vol. 74, no. 5, pp. 1814-1822, 2011.

[5] S.-S. Chang, J. K. Kim, and X. R. Wang, "Modified block iterative algorithm for solving convex feasibility problems in Banach spaces," Journal of Inequalities and Applications, vol. 2010, Article ID 869684, 14 pages, 2010.

[6] P. L. Combettes and S. A. Hirstoaga, "Equilibrium programming in Hilbert spaces," Journal of Nonlinear and Convex Analysis, vol. 6, no. 1, pp. 117-136, 2005.

[7] E. Blum and W. Oettli, "From optimization and variational inequalities to equilibrium problems," The Mathematics Student, vol. 63, no. 1-4, pp. 123-145, 1994.
[8] T. Igarashi, W. Takahashi, and K. Tanaka, "Weak convergence theorems for nonspreading mappings and equilibrium problems," in Nonlinear Analysis and Optimization, S. Akashi, W. Takaxashi, and T. Tanaka, Eds., pp. 75-85, Yokohama, Yokohama, Japan, 2009.

[9] S. Iemoto and W. Takahashi, "Approximating common fixed points of nonexpansive mappings and nonspreading mappings in a Hilbert space," Nonlinear Analysis. Theory, Methods \& Applications, vol. 71, no. 12, pp. e2082-e2089, 2009.

[10] Y. Kurokawa and W. Takahashi, "Weak and strong convergence theorems for nonspreading mappings in Hilbert spaces," Nonlinear Analysis. Theory, Methods \& Applications, vol. 73, no. 6, pp. 1562-1568, 2010.

[11] K. S. Kim, "Approximating common fixed points of nonspreading-type mappings and nonexpansive mappings in a Hilbert space," Abstract and Applied Analysis, vol. 2012, Article ID 594218, 18 pages, 2012.

[12] L.-C. Ceng, S. Al-Homidan, Q. H. Ansari, and J.-C. Yao, "An iterative scheme for equilibrium problems and fixed point problems of strict pseudo-contraction mappings," Journal of Computational and Applied Mathematics, vol. 223, no. 2, pp. 967-974, 2009.

[13] S. Wang, G. Marino, and Y.-C. Liou, "Strong convergence theorems for variational inequality, equilibrium and fixed point problems with applications," Journal of Global Optimization, vol. 54, no. 1, pp. 155-171, 2012.

[14] X. Qin, S. Y. Cho, and S. M. Kang, "An extragradient-type method for generalized equilibrium problems involving strictly pseudocontractive mappings," Journal of Global Optimization, vol. 49, no. 4, pp. 679-693, 2011.

[15] Y. Shehu, "A new iterative scheme for a countable family of relatively nonexpansive mappings and an equilibrium problem in Banach spaces," Journal of Global Optimization, vol. 54, no. 3, pp. 519-535, 2012.

[16] X. Qin, S. Y. Cho, and S. M. Kang, "Iterative algorithms for variational inequality and equilibrium problems with applications," Journal of Global Optimization, vol. 48, no. 3, pp. 423-445, 2010.

[17] Y. Liu, "Strong convergence theorems for variational inequalities and relatively weak nonexpansive mappings," Journal of Global Optimization, vol. 46, no. 3, pp. 319-329, 2010.

[18] U. Kamraksa and R. Wangkeeree, "Existence theorems and iterative approximation methods for generalized mixed equilibrium problems for a countable family of nonexpansive mappings," Journal of Global Optimization, vol. 54, no. 1, pp. 2746, 2012.

[19] A. Moudafi, "Weak convergence theorems for nonexpansive mappings and equilibrium problems," Journal of Nonlinear and Convex Analysis, vol. 9, no. 1, pp. 37-43, 2008.

[20] L.-C. Ceng and J.-C. Yao, "A hybrid iterative scheme for mixed equilibrium problems and fixed point problems," Journal of Computational and Applied Mathematics, vol. 214, no. 1, pp. 186201, 2008.

[21] S.-s. Chang, H. W. Joseph Lee, and C. K. Chan, "A new method for solving equilibrium problem fixed point problem and variational inequality problem with application to optimization," Nonlinear Analysis. Theory, Methods \& Applications, vol. 70, no. 9, pp. 3307-3319, 2009.

[22] Y. J. Cho, X. Qin, and J. I. Kang, "Convergence theorems based on hybrid methods for generalized equilibrium problems and fixed point problems," Nonlinear Analysis. Theory, Methods \& Applications, vol. 71, no. 9, pp. 4203-4214, 2009. 
[23] Y. Song and H. Wang, "Convergence of iterative algorithms for multivalued mappings in Banach spaces," Nonlinear Analysis. Theory, Methods \& Applications, vol. 70, no. 4, pp. 1547-1556, 2009.

[24] N. Shahzad and H. Zegeye, "On Mann and Ishikawa iteration schemes for multi-valued maps in Banach spaces," Nonlinear Analysis. Theory, Methods \& Applications, vol. 71, no. 3-4, pp. 838-844, 2009.

[25] M. Eslamian and A. Abkar, "One-step iterative process for a finite family of multivalued mappings," Mathematical and Computer Modelling, vol. 54, no. 1-2, pp. 105-111, 2011.

[26] A. Kangtunyakarn, "Convergence theorem of common fixed points for a family of nonspreading mappings in Hilbert space," Optimization Letters, vol. 6, no. 5, pp. 957-961, 2012.

[27] G. Marino and H.-K. Xu, "Weak and strong convergence theorems for strict pseudo-contractions in Hilbert spaces," Journal of Mathematical Analysis and Applications, vol. 329, no. 1, pp. 336-346, 2007.

[28] M. O. Osilike and D. I. Igbokwe, "Weak and strong convergence theorems for fixed points of pseudocontractions and solutions of monotone type operator equations," Computers \& Mathematics with Applications, vol. 40, no. 4-5, pp. 559-567, 2000. 


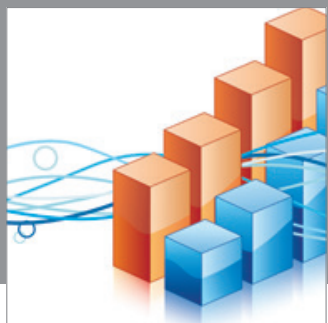

Advances in

Operations Research

mansans



The Scientific World Journal
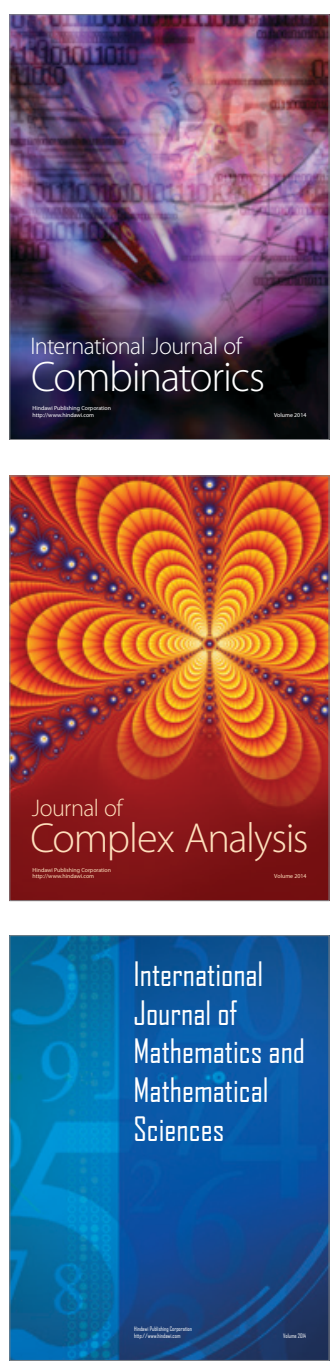
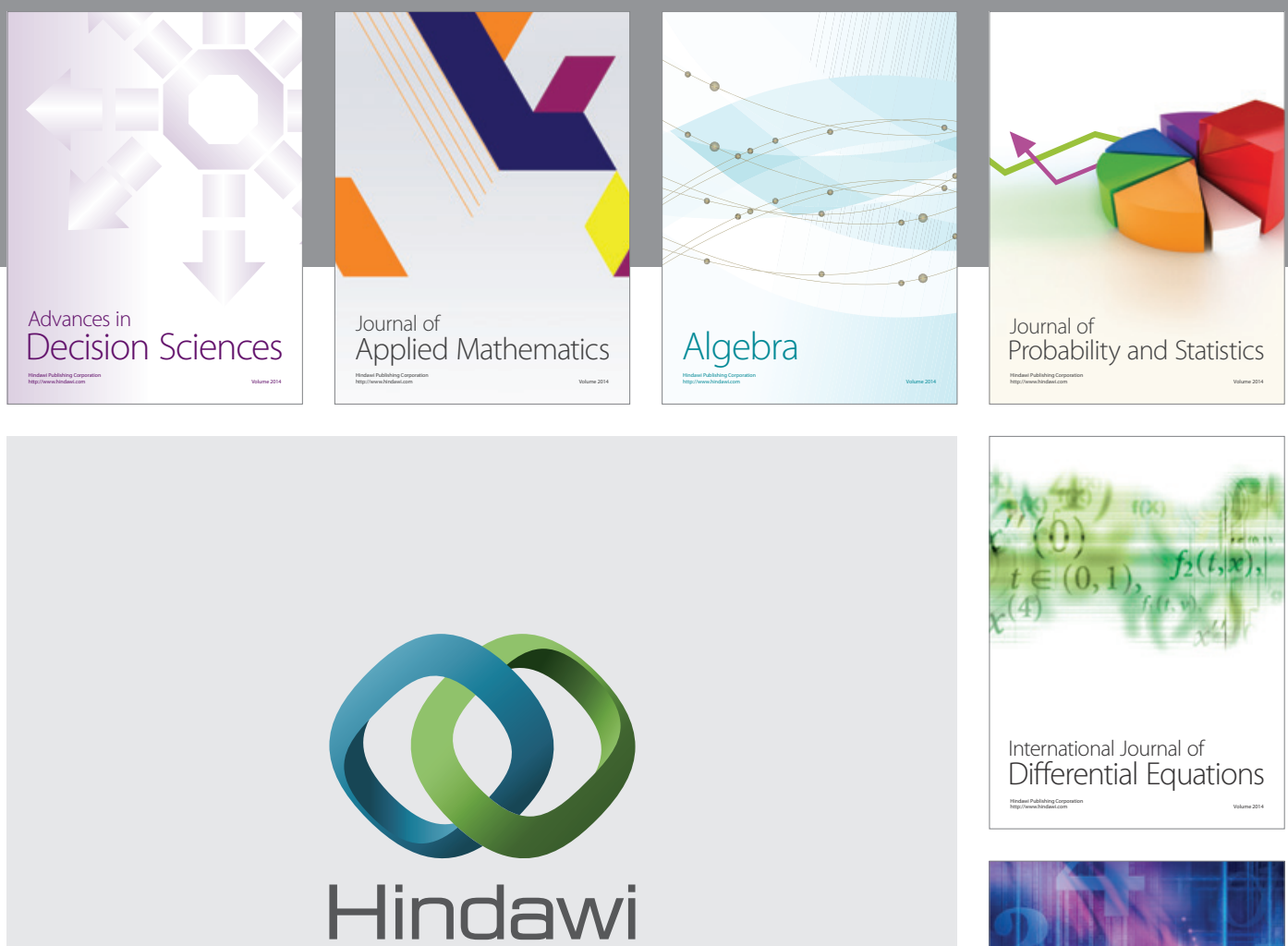

Submit your manuscripts at http://www.hindawi.com
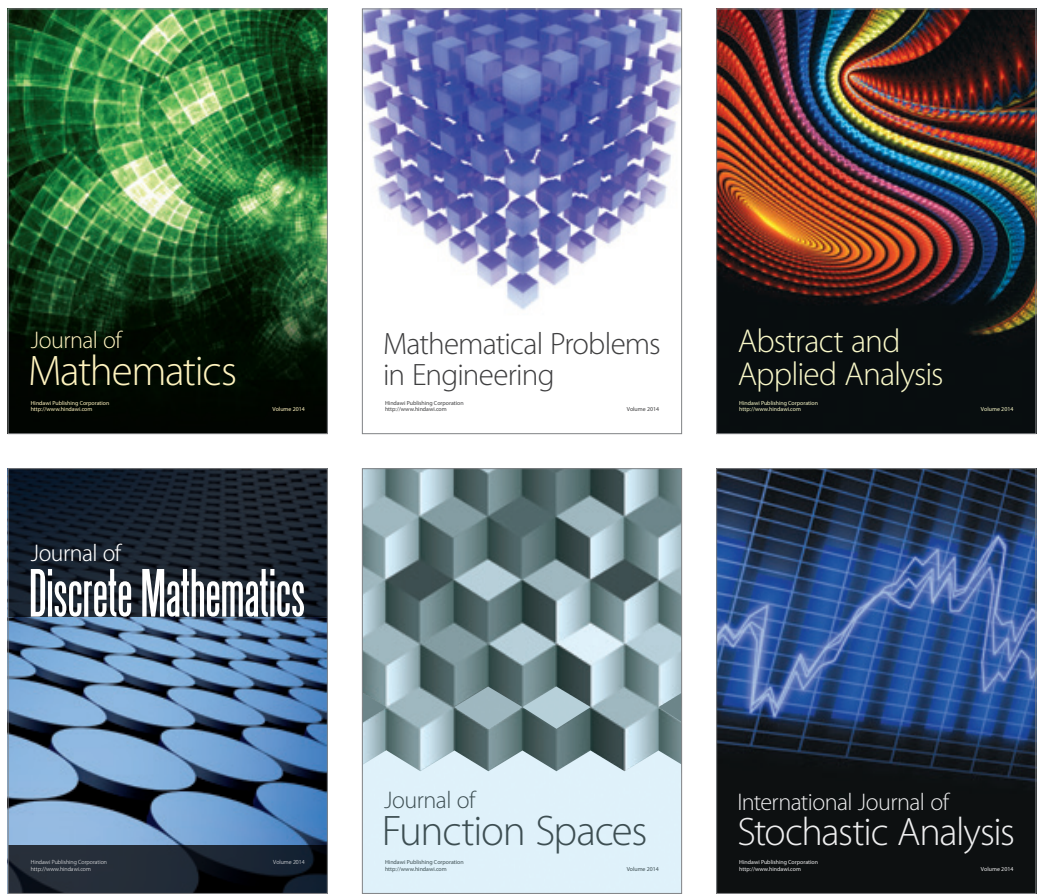

Journal of

Function Spaces

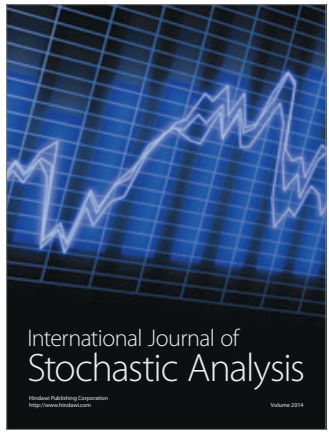

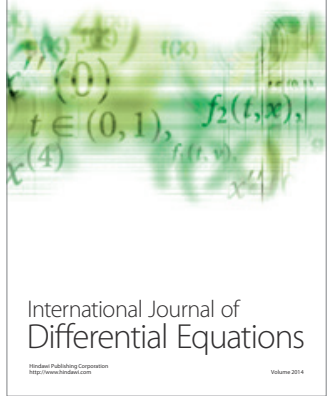
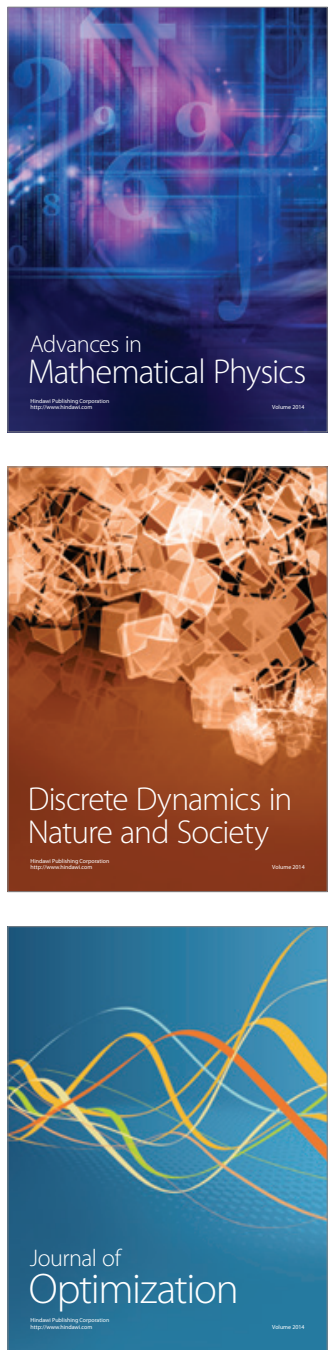